\title{
An Incomplete Information Static Game Evaluating Community-Based Forest Management in Zagros, Iran
}

\author{
Mehdi Zandebasiri ${ }^{1}{ }^{\complement}$, José António Filipe ${ }^{2, *} \mathbb{C}^{\circ}$, Javad Soosani ${ }^{3}$, Mehdi Pourhashemi ${ }^{4}{ }^{\oplus}$, \\ Luca Salvati ${ }^{5,6}$, Mário Nuno Mata 7,8 (1) and Pedro Neves Mata 9,10 \\ 1 Department of Forestry, Faculty of Natural Resources, Behbahan Khatam Alanbia University of Technology, \\ Behbahan 63616-47189, Iran; mehdi.zandebasiri@yahoo.com \\ 2 Department of Mathematics, ISTA-School of Technology and Architecture, University Institute of \\ Lisbon (ISCTE-IUL), Information Sciences, Technologies and Architecture Research Center (ISTAR-IUL), \\ Business Research Unit-IUL (BRU-IUL), 1649-026 Lisbon, Portugal \\ 3 Department of Forestry, Faculty of Agriculture \& Natural Resources, Lorestan University, \\ Khorramabad 6814-94414, Iran; soosani.j@lu.ac.ir \\ 4 Forest Research Division, Research Institute of Forests and Rangelands, Agricultural Research Education and \\ Extension Organization (AREEO), Tehran 14968-13111, Iran; pourhashemi@rifr-ac.ir \\ 5 Council for Agricultural Research and Economics (CREA), Research Center for Forestry and Wood, \\ Viale S. Margherita 80, I-52100 Arezzo, Italy; luca.salvati@crea.gov.it \\ 6 Global Change Research Institute of the Czech Academy of Sciences, \\ Lipová 9, CZ-37005 České Budějovice, Czech Republic \\ 7 Lisbon Accounting and Business School Lisbon Polytechnic Institute, Avenida Miguel Bombarda 20, \\ 1069-035 Lisbon, Portugal; mnmata@iscal.ipl.pt \\ 8 Polytechnic Institute of Santarém, School of Management and Technology (ESGTS-IPS), \\ 2001-904 Santarém, Portugal \\ 9 ISTA-University Institute of Lisbon (ISCTE-IUL), 1649-026 Lisbon, Portugal; pedro_mata@iscte-iul.pt \\ 10 ESCS-Escola Superior de Comunicação Social, Instituto Politécnico de Lisboa, 1549-014 Lisbon, Portugal \\ * Correspondence: jose.filipe@iscte.pt
}

Received: 30 January 2020; Accepted: 23 February 2020; Published: 26 February 2020

check for updates

\begin{abstract}
The present study adopts a game theory approach analyzing land-use planning in Zagros forests, Iran. A Static Game of Incomplete Information (SGII) was applied to the evaluation of participatory forest management in the study area. This tool allows a complete assessment of sustainable forest planning producing two modeling scenarios based on (i) high and (ii) low social acceptance. According to the SGII results, the Nash Bayesian Equilibrium (NBE) strategy suggests the importance of landscape protection in forest management. The results of the NBE analytical strategy show that landscape protection with barbed wires is the most used strategy in local forest management. The response to the local community includes cooperation in conditions of high social acceptance and noncooperation in conditions of low social acceptance. Overall, social acceptance is an adaptive goal in forest management plans.
\end{abstract}

Keywords: decision making; forest management; Nash Bayesian Equilibrium (NBE); Harsanyi's Transformation (HT)

\section{Introduction}

Forestry refers to the use of forest landscapes to achieve specific objectives [1]. Community forestry results from the management of woodlands when the aim is to create a specific benefit for the neighboring communities [2,3]. Forest management issues are crucial for environmental sustainability since they involve the intervention of several different stakeholders (e.g., the state, private companies, 
local forest users). Coordinating local commitments and engaging civil society to reconcile management asymmetry and build consensus can promote sustainable outcomes [4,5]. In these regards, a modeling approach, providing a set of interactive scenarios in forest management contributes to more effective policies addressing socioeconomic problems of Local Communities (LCs). For the adequate use of forest resources, communities should take part in their management. The idea of a Community Based Forest Management (CBFM) was first developed in the mid-1970s [4]. CBFM is a way of authorizing Local Communities (LCs) of a forest to participate in the decision-making processes [4]. This kind of forest managed by CBFM is called 'community forests', which provide economic and environmental services to more than half a billion LCs worldwide [6]. LCs are a source of a wide range of strengths but also threats for forest policy makers. LCs have goals that usually are diverse from the ones of official forest managers, in terms of Wood Products (WP)-fuel wood, bark or cork, and Non-Wood Forest Products (NWFP), as the case of mushrooms, goat feeding or fruits, for instance.

Identifying and determining LCs' goals is the basis for any attempt to manage forests, especially those in problematic socioeconomic situations. The choice of an adaptive strategy within LCs choices is one of the most influential decisions in CBFM. One option for modeling LC choices when designing future forest strategies is integrating already possible strategies for social values of management systems. It is remarkable to note that recent studies found a negative correlation between the formalization of forest monitoring and various measures of trust in LC strategies. Hence, the trust in LCs strategies can replace forest management rules [7]. It means that relying on LCs can represent a substitute for forest managers and personnel, reducing management costs if they are effectively utilized. LCs can themselves have a monitoring role in forestry practices.

Game Theory is a commonly used tool for analyzing community issues in order to attain a systematic approach and support for strategic situations. Game theory has been proposed for agents' decision making that is particularly relevant in conflict situations. This condition may occur when stakeholders are in competition with each other to attain certain goals $[8,9]$. CBFM is influenced by certain goals from forest managers and LCs. These goals can themselves be competing or conflicting. Hence, game theory is a suitable tool for analysis and understanding of forestry strategies. If used correctly, game theory can provide a refined analysis framework for successful policy implementation. Literature dealing with game theory models applied to forestry issues is relatively poor. For instance, Shahi and Kant [10] applied game theory to Joint Forest Management (JFM) in India, proposing a specific game for JFM modeling with four evolutionary strategy equilibriums: cooperators, defectors, defectors-enforcers, and cooperators-enforcers. The results from this study showed that this game has two asymptotically strong equilibriums: defectors-enforcers equilibrium, and cooperators-enforcers equilibrium. Mohammadi Limaei and Lohmander [11] adopted a dynamic game to analyze the timber market in northern Iran. The dynamic features of timber prices derived from the game model were finally applied to estimate the price chain in Iran. Mohammadi Limaei [12] applied a two-person non-zero-sum game to the pulpwood market in Iran.

Soltani et al. [13] applied the game theory between the LCs and state authorities in the Zagros forest (Iran). The results of this study show that a non-cooperative game exists between LCs and the executive management of that forest. Zandebasiri et al. [14] designed a Static Game of Complete Information (SGCI) for Zagros forest modeling the relationship between executive management and LCs. These authors found that the SGCI model has two Nash Equilibriums (NEs) in a composition of conservation of forest resources with a lack of corporation of the LCs and composition of precipitation storage with the corporation of the LCs. Many of the basic ideas for the game adopted in this paper are similar to the one of Zandebasiri et al. [14]. Also, a recently developed Static Game of Incomplete Information (SGII) method was used to analyze the community's forest management. In SGII, one of the players does not know the payoffs of the other players' strategies. Although game theory is an established method in forest management and policy analysis [10,12-14], to the best of our knowledge, our study is the first to apply SGII to forest management. 
We applied this methodology to a particularly complex ecosystem in Zagros (Iran), regarded as an example of forest landscape has been heavily managed by executive management efforts $[15,16]$, but it needs to develop the involvement of local communities in forest management decisions. The justification or significance of this study is providing principles consistent with local communities and social forestry. The results of this study can not only be useful for the management of local communities, but also for the management of drought and dieback in the forest. Everything in forest management depends on decisions $[17,18]$, and the decisions determine the future of the forests. Based on the results of the game theory method in this research, we present the best options for forest managers.

The main socio-environmental issues in Zagros forests are the socioeconomic problems of local communities [19], the dependency of LC to forest resources [20], cattle overgrazing in woodland [21,22] and the consequent forest degradation [22,23]. For these reasons, the role of local communities in these forests is vital. The related ecosystem needs participatory management, enhancing opportunities and avoiding threats in forest utilization [24]. One of the main problems that LCs use to face is cattle overgrazing in forest land [22]. This issue conflicts with the technical demands of forest managers. The executive management will encircle these forests with barbed wire [25]. Hence, one of the main issues in this theme is forest conservation [16]. Additionally, for about eight years (from 2011 onwards), forest die-back has been the most widespread problem in Zagros [14], particularly in the aridest districts. To face these problems, the executive management of Zagros forests was increasingly oriented toward two strategies: (i) forest conservation and (ii) precipitation storage [15].

At the same time, local communities have employed informal responses to such problems: (i) cooperation, and (ii) non-cooperation with executive management strategies [14]. Based on these premises, it is clear how all executive management decisions and strategies are directly related to LCs response and to the social acceptance of such programs [16]. Local residents have traditional knowledge that may contribute significantly to effective forest management. In this context, the response of each local community's activity creates new information for the executive management of forests, and each of the executive management decisions causes new LC feedback [20]. According to such dynamics, a game is proposed here between the executive management and LCs using a Static Game of Incomplete Information (SGII) model. The model was built-up to specifically focus on two objectives of forest management in Zagros: (i) reducing the pressure of resident livestock on forest landscape and (ii) enhancing precipitation storage to cope with droughts and containing oak forest degradation.

\section{Methodology}

\subsection{Game Theory}

Game theory provides models for decision making for situations in which decision makers show interdependence and reciprocity. The condition when a decision-making process is affected by decision-makers where each decision relates to another decision is a process called the game [14]. In these situations, the suitable alternative for policy-making depends on other alternatives affecting decision-makers. For quantifying the policy-making, a payoff matrix is formed. Table 1 shows a payoff matrix for a two-player game.

Table 1. A payoff matrix for a 2-player game.

\begin{tabular}{ccc}
\hline & $S_{Y 1}$ & $S_{Y 2}$ \\
\hline$S_{X 1}$ & $\left(x_{11}, y_{11}\right)$ & $\left(x_{12}, y_{12}\right)$ \\
\cline { 2 - 3 }$S_{X 2}$ & $\left(x_{21}, y_{21}\right)$ & $\left(x_{22}, y_{22}\right)$ \\
\hline
\end{tabular}

$S x_{1}$ is the first strategy and $S x_{2}$ is the second strategy of the player. Strategies of player $Y$ are defined in the same way. Numbers $\left(\mathrm{x}_{11}, \mathrm{y}_{11}\right)$ denote that if the combination of $\mathrm{S}_{\mathrm{X} 1}$ and $\mathrm{S}_{\mathrm{Y} 1}$ strategies is 
applied by the two players, the benefit of players $X$ and $Y$ is equal respectively to $x_{11}$ and $y_{11}$. In this game, problem answers are called Nash Equilibriums (NEs) of the game. The above matrix is valid for a two player game. In general, if a game has $n$ players is presented as an $n$-player game. The above matrix has two strategies for each player. In general, when a game has $\mathrm{n}$ strategies for each player, it is represented by a non-matrix. The first step consists of presenting the game. A set of players in an $N$-player game can be represented by $N=\{1,2,3, \ldots, n\}$. Strategies of the $i$-th player can be represented by $S_{i}=\left\{A_{1} * A_{2} * A_{3} * \ldots * A_{n}\right\}$, where $\mathrm{A} 1, \ldots$, An are $\mathrm{n}$ different strategies, $i \in N$. The rows and columns show the strategies of each player. The rows of this matrix depend on the number of strategies of one player and the column of this matrix depends on the number of strategies of the other player(s).

Games having simultaneous decisions among players are called Static Games (SGs), and games with the one-after-another decisions are called Dynamic Games (DGs). SGs are divided in Static Games of Complete Information (SGCI) and Static Games of Incomplete Information (SGII). When a player knows the payoffs of the other player(s), the game is called SGCI. On the contrary, in SGII, one (or more) player(s) does (do) not know the payoffs of strategies of the other players. Equilibriums of the SGCI and SGII are called, respectively, Nash Equilibrium (NE) and Nash Bayesian Equilibrium (NBE) [8,9].

\subsection{Study Area}

"Zagros forests" is the name for a vast system of forest landscapes in northwest, west, and southwest of Iran. This region contains 5 million hectares of forests (44 percent of Iran's forest area). The area of these forests had already contained 10 million hectares long ago. Due to the intense exploitation of word products, the forest area decreased to five million hectares in the present days. Brant's oak (Quercus brantii Lindl) is the dominant species in the landscape [26-28]. The study area includes the Watershed of Tang-e Solak in the province of Kohgiluyeh, South-western Iran. Tang-e Solak forest is located in Likak (Bahmaee) city in Kohgiluyeh province and includes fragmented cropland producing wheat and barley. In this area, natural cypress trees and oak stands form a unique stand of cypress-oak [29]. Local populations living in this region have progressively moved to urban areas in search for job, facilities, and higher income. Forest landscapes in Zagros are legally state-owned. Zagros forests were declared state forests by the law in 1962 [1]. However, the executive management of forestry projects had many conflicts with LCs in this forest. More specifically, there is a considerable dependency between LCs and the forest because of the traditional exploitation of forest production by LCs, with consequent degradation of forest structure through informal cuts of wood. As a consequence, the Zagros forest has been extensively coppiced $[23,30]$. In the last decade, a new issue was observed in the Zagros forest, since an extensive oak die-back occurred [31]. Arabic dust coming from neighboring Arab countries, climate change, and the intense summer heat, seem to be the main reason for this die-back [14]. This phenomenon requires specific planning to reduce the risk of forest die-back.

In the current situation, executive management has applied the Forest Management Plan (FMP) for the region with a focus on forest resources conservation [14]. By 1998, the management unit for Zagros forests concerned large watershed areas, but since then, the management unit in these forests changed to the level of customary rural development to include LCs [32]. In order to fix a sustainable utilization rate for local communities, the goal was to reach participatory planning decisions in line with the traditional forest related knowledge [33]. The investigated spatial level of the system was reduced to a specific area representative of the whole system: in our case, a watershed district was selected to model executive management strategies. The scores of each strategy were assumed to be variable in different local contexts depending on social and environmental conditions.

Although the intervention scale in Zagros forests can be broadened, it is a concern that the principle of unity of command — which is one of the principles of management [18] — may be lost at a larger scale. Accordingly, the present study was carried out with the aim to consider the level of decision-making at the level of the customary system rather than focusing on larger scales. 


\subsection{Selection of the Type of Game}

This study is part of a larger research in Zagros forests of Iran on game theory methods and its application in participatory management. In this series of researches, we seek to explore the application of various types of game theory and its applications in the optimal management of local communities for forest conservation. To examine the relationship between local communities and executive management, for the first time in 2017, we used SGCI for this concept [14]. For this study, we selected the SGII method and in future researches; we will intend to use dynamic gaming models.

The questions that will be asked to experts to each method differ from the other method once each method needs separate data. Hence, in this study we can only use SGII method because the assumptions of the questions asked to the experts and the assumptions of the analyst team in this study were only assumptions of the SGII method.

\subsection{Model Set-Up and Calculation}

The most important issue in managing Zagros forests is the participation of local people. The most important reason for the failure of past projects in Zagros forests was the lack of social acceptance of forest planning $[5,7,28,30]$. Therefore, scenarios of social acceptance were defined by local communities. The reason for constructing scenarios is to focus on the issue of social acceptance in Zagros forestry projects. Based on these assumptions, two modeling scenarios were defined for the SGII: (1) a High social acceptance scenario (H) and (2) a Low social acceptance scenario (L). The high social acceptance scenario was used to illustrate forest sites that have appropriate social conditions. These forests may have few socioeconomic problems. Conversely, the low social acceptance scenario was applied to illustrate forest sites that have inappropriate social conditions.

These two scenarios have relevant consequences on computation. If social acceptance of projects increases, the success of the executive management programs will be highly probable, while if social acceptance of plans is reduced, the executive management plans will fail. Each of these scenarios may occur when executive management impacts FMPs. Consequently, SGCI cannot completely evaluate this game. Executive management can predict only the Stakeholder Analysis (SA) of the FMP. The SA of the FMP relates to land-use conflicts, the economic condition of local communities, and planning flexibility to the living standards of the area. Thus, model inputs were two scenarios with the SGII and prior SGCI. The purpose of applying the game theory of game in this section is to assess if the result of the implementation of executive management programs is in contrast to the local communities' practices in forest management.

\subsection{Building Up the Payoff Matrix}

A separate matrix was built-up for each scenario. Priority values were determined by asking three experts who were specifically selected for the estimation of payoffs of the game to answer the question of what privileges the expert had given to the emergence of different combinations of local community and executive management strategies. The higher the score, the more likely it will happen. Average values in each cell are considered as the number of matrices per cell. Likert scale numbers were calculated based on the mean of experts' opinions in each cell. The model's calculation was based on the SGII algorithm. Because of the complexity of the SGII model and combination of strategies in two conditions (i.e., high and low social acceptance), three experts were specifically selected for the estimation of payoffs of the game. The benefits of the different strategies for key players were evaluated using a Likert scale. Expert's opinions were used at this stage. The average score of each strategy was calculated based on the opinions of experts in the form of a Likert scale. Since the application of SGII is new, a short explanation of this theory is presented below. The normal form of the SGII for n players is as follows [8]:

$$
N=\{1,2,3, \ldots, n\}
$$


where $n$ is the number of the total of players.

$$
A_{i}=\left\{a_{1}, a_{2}, a_{3}, \ldots, a_{n}\right\}
$$

where $A i$ is the collection of strategies of each player.

$$
S=\left\{A_{1} * A_{2} * A_{3} * \ldots * A_{n}\right\}
$$

where $S$ is the combination of strategies of all players. Strategies for each player are divided into Pooling Strategies (PSs) and Separating Strategies (SSs).

$$
T_{i}=\left\{t_{1}, t_{2}, t_{3}, \ldots, t_{n}\right\}
$$

where $T_{i}$ is the set of conditions for each player.

$$
T=\left\{T_{1} * T_{2} * T_{3} * \ldots * T_{n}\right\}=\left\{t:\left(t_{1}, t_{2}, t_{3}, \ldots, t_{n}\right), t_{1} \in T_{1}, \ldots, t_{n} \in T_{n}, t \in T\right\}
$$

where $T$ is the set of conditions for the game.

$$
P_{r}=P_{i}\left(t_{-i} \mid t_{i}\right) \forall t_{i} \in T_{i}, \forall t_{-i} \in T_{-i}, \forall i \in N
$$

where $P_{r}$ is a prior belief for each player and $T_{-i}$ is a set of conditions for competitor players.

$$
u_{1}\left(q_{1}, q_{2} \mid\left(c, c_{H}\right)\right)=\left[\begin{array}{l}
\left(a-c-\left(q_{1}+q_{2}\left(c_{H}\right)\right) q_{1} i f Q<a\right. \\
-c q_{1} i f Q \geq a
\end{array}\right]
$$

where $u_{1}$ is the payoff of player $1, q 1$, and $q 2$ are values of payoff matrix for player 1 and 2 , respectively, $T_{1}=\{c\}, T_{2}=\left\{C_{l}, C_{h}\right\}$ and $q_{2}\left(c_{H}\right)$ is the value of payoff matrix for player 2 in $\mathrm{H}$ condition.

$$
u_{1}\left(q_{1}, q_{2} \mid\left(c, c_{L}\right)\right)=\left[\begin{array}{l}
\left(a-c-\left(q_{1}+q_{2}\left(c_{L}\right)\right) q_{1} i f Q<a\right. \\
-c q_{1} i f Q \geq a
\end{array}\right]
$$

where $q_{2}\left(c_{L}\right)$ is the value of payoff matrix for player 2 under L condition.

$$
\begin{aligned}
& u_{2}\left(q_{1}, q_{2} \mid\left(c, c_{L}\right)\right)=\left[\begin{array}{l}
\left(a-c_{L}-\left(q_{1}+q_{2}\right) q_{1} i f Q<a\right. \\
-c_{L} q_{2} i f Q \geq a
\end{array}\right] \\
& u_{2}\left(q_{1}, q_{2} \mid\left(c, c_{H}\right)\right)=\left[\begin{array}{l}
\left(a-c_{H}-\left(q_{1}+q_{2}\right) q_{1} i f Q<a\right. \\
c_{H} q_{2} i f Q \geq a
\end{array}\right]
\end{aligned}
$$

where $u_{2}$ is the payoff of player 2 in Equations (9) and (10).

The extensive form of SGII is called Harsanyi's Transformation (HT). HT is the first step in the resolution of SGII. An artificial player is defined in HT that will start the game by defining conditions of each player. The graphical model of HT is shown in Figure 1.

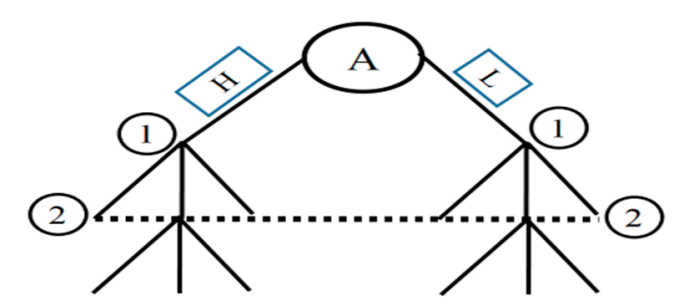

Figure 1. The graphical model of Harsanyi's Transformation (HT).

In Figure 1, signal A denotes the artificial environment to start the game, $\mathrm{H}$ and $\mathrm{L}$ are high and low SA conditions, and (1) and (2) are game players; player 2 does not know for sure that player 1 is $\mathrm{H}$ 
or L. HT was formed before Posterior belief $\left(P_{0}\right)$ is calculated for players. $P_{o}$ is calculated from the below equation according to Bayes' rule:

$$
P_{o}\left(t_{i-1} \mid t_{i}\right)=\frac{P\left(t_{-i}, t_{i}\right)}{P\left(t_{i}\right)}=\frac{P\left(t_{i}\right)}{\sum_{t_{-i} \in T_{-i}} p\left(t_{-i,}, t_{i}\right)}
$$

where $P_{o}$ is a posterior belief, $t=\left\{t_{1}, t_{2}, t_{3}, \ldots, t_{n}\right\} \forall t_{i} \in T_{i}$.

NBE is calculated from a combination of below strategies following the calculation of $P_{o}$ :

$$
\underset{s_{i} \in S_{i}}{=} \max \sum u_{i}\left(s_{1}^{*}\left(t_{1}\right), \ldots, s_{i}, s_{i+1}^{*}\left(t_{i+1}\right), \ldots, s_{n}^{*}\left(t_{n}\right) \mid t_{i}, t_{-i}\right) P\left(t_{-i} \mid t_{i}\right)
$$

where $s^{*}=\left(s_{1}{ }^{*}\left(t_{1}\right), \ldots, s^{*}{ }_{n}\left(t_{n}\right)\right) \in S$

$$
N=\{\text { Local resident, Executive management }\}
$$

Executive management and the local community are the main stakeholders in participatory management of the Zagros forests [19].

$$
S_{1}=\{C, N\}, S_{2}=\{E, S\}
$$

$C$ and $N$ are acronyms of Cooperation and Non-cooperation of local community. $E$ and $S$ are acronyms of encirclement and saving rainfall strategies of executive management, respectively. Encirclement is applied for protection of forests with barbed wire. Saving rainfall is a strategy to preserve water under oak degradation.

$$
\begin{gathered}
S=S_{1} * S_{2}=\{(C, E),(C, S)(N, E),(N, S)\} \\
T_{1}=\{H, L\}, T_{2}=\{x\} \\
T=T_{1} * T_{2}=\{(H, x),(L, x)\} \\
P_{1}(x \mid H)=P_{1}(x \mid L)=1, P_{2}(L \mid x)=1-P, P_{2}(H \mid x)=1-p
\end{gathered}
$$

\section{Results}

Results for payoff matrixes for SGII are shown in Table 2.

Table 2. A payoff matrix for P probability and $\mathrm{H}$ condition (panel A) or L condition (panel B).

\begin{tabular}{ccc}
\hline & $\mathrm{E}$ & $\mathrm{S}$ \\
\hline $\mathrm{C}$ & $(3,3)$ & $(3,2)$ \\
\cline { 2 - 3 } $\mathrm{N}$ & $(1,3)$ & $(1,1)$ \\
\hline \multicolumn{3}{c}{$(\mathbf{a})$} \\
\hline \multicolumn{3}{c}{$\mathrm{E}$} \\
$\mathrm{C}$ & $(1,3)$ & $(2,1)$ \\
$\mathrm{N}$ & $(3,3)$ & $(2,1)$ \\
\hline
\end{tabular}

(b)

Table 2a shows that in the high social acceptance scenario, forest conservation can perform very well, and it acquires a high score. Table $2 \mathrm{~b}$ shows that in the low social acceptance scenario, forest conservation cannot perform very well and score high; however, forest conservation is a key issue in the Zagros forests. The graphical model of HT for the game is shown in Figure 2. 


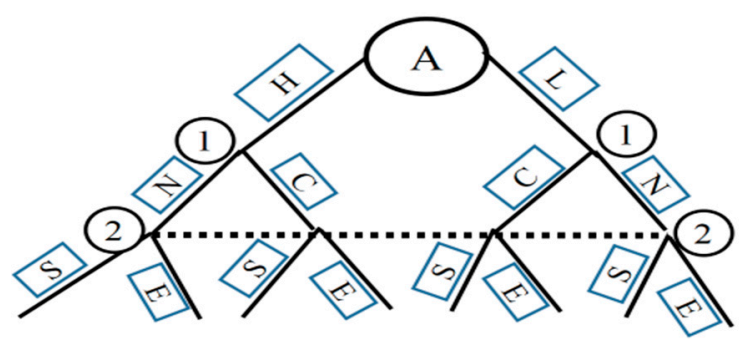

Figure 2. The graphical model of Harsanyi's Transformation for the selected game.

Interaction of strategies in the normal form of SGII is shown in Table 3.

Table 3. Interaction of strategies in the normal form of SGII.

\begin{tabular}{ccc}
\hline & $\mathrm{E}$ & $\mathrm{S}$ \\
\hline $\mathrm{CC}$ & $(2 P+1,3)$ & $(P+2, P+1)$ \\
$\mathrm{CN}$ & $(3,3)$ & $(P+2, P+1)$ \\
$\mathrm{NC}$ & $(1,3)$ & $(2-P, 1)$ \\
$\mathrm{NN}$ & $(-2 P+3,3)$ & $(-P+2,1)$ \\
\hline
\end{tabular}

This table is the basis of the difference between the results of SGCI method and the SGII method in game theory that numbers in Table 3 were extracted from Equation (11).

$$
U_{1}(C C, E)=3 P+(1-P)=2 P+1
$$

The $P$ number is a number for the probability of the $\mathrm{H}$ state in Figure 2 which occurs with high social acceptance for executive management programs.

$$
U_{2}(C C, E)=3 P+3(1-P)=3
$$

The $(1-P)$ number is a number for the probability of the L state in Figure 2 which occurs with low social acceptance for executive management programs.

$$
\begin{aligned}
& U_{1}(C C, S)=3 P+2(1-P)=P+2 \\
& U_{2}(C C, S)=2 P+(1-P)=P+1
\end{aligned}
$$

Number 3 represents the highest number among the results in these equations. The results of Equations (21) and (22) can only be approximated to the number 3 when the $P$ number is equal to 1 . These situations occur only when social acceptance is $100 \%$ probable. The $S$ strategy (saving rainfall) is very important for the Zagros forests because these forests are facing drought today. If Zagros Forests Management wants to focus on the benefits of this strategy and shift the equilibrium of the game to this strategy, they must plan for social acceptance.

$$
\begin{aligned}
& U_{1}(C N, E)=3 P+3(1-P)=3 \\
& U_{2}(C N, E)=3 P+3(1-P)=3
\end{aligned}
$$

Equations (23) and (24) earned high scores for both executive management and local communities because number 3 represents the highest number among the results in these equations. When both executives and local communities have a high score, the equilibrium of the game can be here.

$$
\begin{gathered}
U_{1}(N C, E)=P+(1-P)=1 \\
U_{2}(N C, E)=3 P+3(1-P)=3
\end{gathered}
$$


In Equation (25), the interests of local communities have been diminished, as only forest conservation reduces their interests. However, the score of management processes is raised in Equation (26).

$$
\begin{gathered}
U_{1}(N N, E)=P+3(1-P)=-2 P+3 \\
U_{2}(N N, E)=3 P+3(1-P)=3
\end{gathered}
$$

Similar to Equations (25) and (26) the interests of local communities have been diminished in forest conservation.

$$
\begin{aligned}
& U_{1}(C N, S)=3 P+2(1-P)=P+2 \\
& U_{2}(C N, S)=2 P+(1-P)=P+1
\end{aligned}
$$

Equations (29) and (30) show that if local communities do not cooperate, the scores for both executive management and local communities will decrease.

$$
\begin{gathered}
U_{1}(N C, S)=P+2(1-P)=-P+2 \\
U_{2}(N C, S)=P+(1-P)=1
\end{gathered}
$$

The results of Equations (30) and (31) show low numbers $((-P+2)$ numbers and 1 indicate this) because of the noncooperation approach for the first operation in the above equations.

$$
\begin{gathered}
U_{1}(N N, S)=P+2(1-P)=-P+2 \\
U_{2}(N N, S)=P+(1-P)=1
\end{gathered}
$$

In the non-cooperative state of local communities, the benefits of both executive management and local communities will be reduced. $(-P+2)$ numbers and 1 indicate this.

Accordingly, BNE is calculated after defeated strategies were erased.

$$
N B E=(C N, E)
$$

According to Equations (19)-(34), NBE strategies illustrated in Equation (35) were imported to SGII equilibrium for participatory management in Zagros forest. Participatory management can include different roles, such as executive roles and decision roles. NBE strategies demonstrate the importance of the $E$ parameter and $C$ and $N$ strategies. The $(C N, E)$ strategy is a strategy through which neither the local community nor the executive government wants to change because if the strategy changes, the payoff in the game will reduce. We found that this balance, which is achieved by integrating the demands of LCs and executive management-with a focus on the enclosure of forests-can be a source of conflicts in the implementation of Zagros forest management plans. Equation (19) and next ones until 35 allow calculating the payoff of other situations. Reaching a new equilibrium that would make precipitation storage more pronounced depends on further examination of native soil conservation methods. This result suggests that precipitation storage programs have not yet found a substantial role in FMPs, likely because of the lack of appropriate allocation of funds for the design and construction of this system. In an NBE state, LCs use a strategy that has the optimal response to selected strategies of the executive management and does not achieve the greatest outcome; instead, they use the best strategy related to decisions of another player [13].

\section{Discussion}

Compared to other game theory analyses, the model proposed in this study is new in forest management. Earlier studies have also emphasized the applications of this theory in forest economics [11,12]. For this reason, forest management knowledge needs basic definitions for the application of this theory to forest management. The static game theory developed in Zagros forests has 
practical applications, whose effectiveness depends on our understanding of mechanisms underlying the Nash equilibrium. More specifically, what forest manager's use in competitive situations depends on the Nash equilibrium? Representing theoretical work formulating a model and commenting on the basic characteristics of the model itself, our study takes advantage of game theory, and the conceptual expansion of this model can be a major innovation for ecosystem management. If developed in a wider model, this theory can be applied to forests under different socio-environmental conditions that can optimize forest management decisions. For instance, local communities in the study area have goals that usually relate to animal feeding, and especially goat feeding, while having no specific goals related to bark collection or cork production. In this landscape, there are very relevant social problems since forest products contribute to LCs subsistence, and thus local residents have an important role in forest management. It should be noted, however, that Zagros forest personals and managers have made great efforts to protect these forests $[15,16]$, but a participatory management approach with local communities must be defined in the decision-making phase for these forests to prevent forest die-back in these landscapes.

Analysis of the NBE shows that E parameter (Encirclement or protection of forests by barbed wires) represents the most used strategy of executive management. The main responses of the local community to this strategy are cooperation in high SA conditions and noncooperation in low SA conditions. According to Shahi and Kant [10] and Soltani et al. [13], the cooperation of LCs has much influence on the game. NBE results present an unfavorable equilibrium in Zagros forests. The attention of stakeholders preferences [34], especially LCs [21], using the potential of forests, land-use planning, and site selection for sustainable development [35] can contribute to NBE strategies aimed at reaching sustainable forest management. In this study, we highlighted the role of the SA factor. SA is an adaptive goal with LCs in FMP. The core concept of forest management in Zagros forests emphasizes the goal-setting in FMP [21]. Goal setting is very important in the process of FMP formulation.

Examples of strategic conditions for forest management in Zagros include: (i) low tree production, (ii) forest structure degradation, (iii) overgrazing [36], (iv) soil erosion, and (v) oak decline [29,37]. The solution to most of these issues is grounded on the traditional agroforestry system existing in Zagros. The concept of agroforestry should be redefined for Zagros forests. Agroforestry is a combination of forestry components with other land-uses for the purpose of land-use planning [22]. In particular, grazing management plans can include organizing the number and timing of livestock in the forest. According to Table 3, SA represents the core of the Zagros forest management, outlining the importance of physical protection and encirclement for executive management. According to assumptions in Table 2, and considering few payoffs for saving rainfalls strategies it can be stated that precipitation saving strategies are not included in NBE. It is important to recognize that rainfall saving is not useful for executive management and has been little considered in its adoption strategies.

The results of this study are very sensitive to the early data collected using a Likert scale. In the current context, executive management has not yet clearly identified many aspects of the technical issues of local communities and their traditional knowledge, which can be seen as the main issue in the interaction between local communities and executive management programs. Contrary to earlier research in this field [14], an SGII method was used in this study. The SGII method is also a way of solving problems in game theory for maximizing the expected payoff of the players by considering the selective strategy of the other players. This is a difference between SGCI and SGII. SGII beliefs become quantities according to Bayes theorem (Equation (11) and Table 3), being an advantage for SGII methods. In SGII methods, the belief of the players indicates the probability of the type of strategy that players can play in the environment of the play (Tables 2 and 3). In a SGII strategy, an artificial player is defined (A symbol in Figure 2). This symbol actually defines the environment of chances and specifies the type or state of each player. SGII methods, players choose their strategies simultaneously, but at least one player does not have enough information about the payoff of the game. In forest management, this is much closer to the real world because, in forest management, uncertainty is always a very important issue for forest managers [32]. Until now, most of the uncertainty sources of forest 
management were ecological and economic [18]. To the best of our knowledge, this is the first time that social uncertainty is defined with an SGII model for forest management.

Our study illustrates an SGII method that is applied to forest management. Several types of game theory, such as an evolutionary game, dynamic game, and static game, including SGCI and SGII, are used to support the decision in forest management and economics, considering two types of agents (executive management and the local community). In this game, the local community has private information about something relevant to its decision making (social acceptance), but the executive management does not know that information. In this situation, it is necessary to model the game by SGII. The SGII contributes to clarify and open the information of a game that has already been hidden. Further approaches should implement a refined model of participatory management with multiple stakeholders such as research institutes, agricultural offices, NGOs, media, and other stakeholders. Further investigation of the performance of other games, like the one proposed by Mohammad Limaei in dynamic game [12], seems to be an appropriate research issue.

Hence, another issue that needs further investigation is the dynamics of the designed game. Dynamic game is another dimension of game theory in which players decide sequentially. In dynamic games, each player makes his own choice after the previous player. In this study, we adopted a static game because the game theory was only recently applied to the complex management of the world's forests by modeling its different branches. Examples of static games in forest management were recently provided [14]. Future studies should be deserved to model forest management under dynamic games. In the dynamic model, the following set of parameters, such as in a static game, are needed:

(1) Players identification,

(2) Set the strategies of each player

(3) Players payoffs functions for each strategy combination

In dynamic games, there are a few additional points to consider [9]:

(1) When does each player move?

(2) What information does each player have on the move?

(3) What can each player do when he moves?

(4) What are the payoffs for players for each sequence of moves?

As such, we need the initial node, nature, decision nodes, terminal node, branches, predecessors, successors, and path of the game in the dynamic state. The initial node shows the start of the game. Decision nodes show the represent the starting point of each player's decision. The terminal node shows the final of the game. Multiple branches can originate from any non-terminal node. The nodes before a given node are called the predecessors, and the nodes after a given node are called the successors. Each path of the game is a sequence of nodes and branches. This creates the first difference in the graphical model for the dynamic game. The dynamic game model for Zagros forest management and their local communities can be designed as follows (Figure 3).

In this representation, the FMP management is assumed as the executive management of Zagros forests. So, logic dictates that the left panel in Figure 3 is the most reasonable representation of a dynamic game model in Zagros. Like static games, dynamic games can be a game with complete or incomplete information. As such, we face complex and wide-ranging situations in design that are best modeled individually. The main purpose is to exploit the benefits of this theory in forest management separately [14]. In dynamic games with complete information conditions, Backward Induction Nash equilibrium can be preferentially used, while in dynamic games with incomplete information conditions, perfect Bayesian Nash equilibrium can be used. Apart from these considerations, it is worth mentioning that forest systems are typically the most stable land-use, which is finally traced by static games representing complexity without providing excessively complex theory and controls for users. 


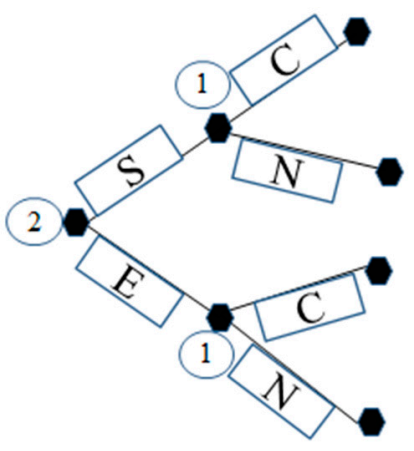

Left

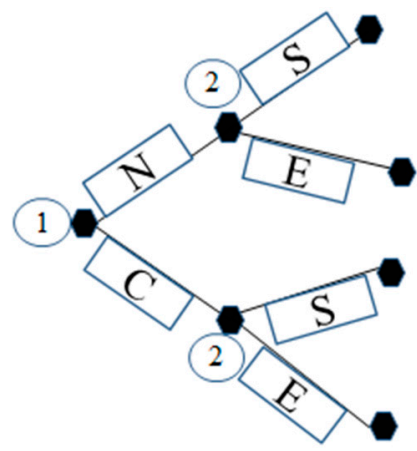

Right

Figure 3. The graphical model of the Zagros forests' management of the dynamic game in a situation where (left) executive management or (right) local communities start the game.

\section{Conclusions}

Sustainable forest management benefited from the use of Multi-Criteria Decision Making (MCDM) methodologies in decision-making processes. In MCDM, what is important is decision-making by decision-makers. The real world of decision-making does not only depend on the decision-maker, but strictly depends on the other players' reaction to the decision situation. Game theories try to study these reactions. Many of the real-world games should be handled in incomplete information, especially in forest management. The performance of SGII is superior because of the high uncertainty in both climatic and social conditions. Our study finally demonstrates that the game between the executive management and the LCs in Zagros was not in the form of a cooperative game. Further examination of evolutionary and collaborative games may contribute greatly to a refined understanding of these deserving issues for forest management.

Author Contributions: Conceptualization, M.Z., J.A.F., J.S. and M.P.; methodology, M.Z. and M.N.M.; Validation, M.Z.; formal analysis, M.Z.; investigation, M.Z., J.S., M.P.; resources, M.Z and J.A.F.; data curation, M.Z.; writing-original draft preparation, L.S., J.A.F. and P.N.M.; writing-review and editing, L.S. J.A.F. and M.Z..; visualization, M.Z, J.S., M.P.; supervision, M.Z.; project administration, M.Z, J.S., M.P.; funding acquisition, J.A.F. and L.S., coordinate with correspondent author, P.N.M. and M.N.M. All authors have read and agreed to the published version of the manuscript.

Funding: Dr. Zandbassiri's doctoral thesis in Lorestan University, Iran was a static game with complete information (SGCI method) on oak decline. This article is out of his thesis, but more on that later a game with incomplete information (SGII method) is designed as an independent research in Behbahan Khatam Alanbia University of Technology (BKAUT). The charge for APC of this article was also paid by Isteki University, Portuguese.

Acknowledgments: The authors thank the Behbahan Khatam Alanbia University of Technology and Lorestan University, for their support. They also thank the Instituto Universitário de Lisboa and ISTAR-IUL, for their support. The authors acknowledge Zagros forest experts to their cooperation with this research. They finally thank of three anonymous reviewers for their valuable comments.

Conflicts of Interest: The authors declare no conflict of interest.

\section{References}

1. Ebrahimi Rostaghi, M. The role of policy-making and decision-making in protection of outside North forests. In Proceedings of the Conference on Protection of Forests in Sustainable Forest Management, Tehran, Iran, 11-13 October 2004; Iranian Society of Forestry: Tehran, Iran, 2005; pp. 137-151.

2. Anup, K.C.; Koirala, I.; Adhikari, N. Cost Benefit Analysis of a Community Forest in Nepal. J. Sustain. For. 2015, 34, 199-213.

3. Anup, K.C. Community Forest Management: A Success Story of Green Economy in Nepal. J. Environ. Sci. 2016, 2, 148-154. 
4. Marasenia, T.R.; Bhattaraib, N.; Karkyb, B.S.; Cadmanc, T.; Timalsinab, N.; Bhandarib, T.S.; Apana, A.; Mad, H.O.; Rawate, R.S.; Vermae, N.; et al. An assessment of governance quality for community-based forest management systems in Asia: Prioritization of governance indicators at various scales. Land Use Policy 2019, 81, 750-761. [CrossRef]

5. $\quad$ Riggs, R.A.; Langston, J.D.; Margules, C.; Boedhihartono, A.K.; Lim, H.S.; Sari, D.A.; Sururi, Y.; Sayer, J. Governance Challenges in an Eastern Indonesian Forest Landscape. Sustainability 2018, 10, 169. [CrossRef]

6. Ellisa, E.A.; Monteroa, S.A.; Gómezb, I.U.H.; Monteroc, J.A.R.; Ellisd, P.W.; Rodríguez-Warde, D.; Reyesf, P.B.; Putzg, F.E. Reduced-impact logging practices reduce forest disturbance and carbon emissions in community managed forests on the Yucatán Peninsula, Mexico. For. Ecol. Manag. 2019, 437, 396-410. [CrossRef]

7. Kahsay, G.A.; Bulte, E. Trust, regulation and participatory forest management: Micro-level evidence on forest governance from Ethiopia. World Dev. 2019, 120, 118-132. [CrossRef]

8. Abdoli, G. Game Theory and its Applications (Incomplete Information, Evolutionary and Cooperative Games); Samt Publication: Tehran, Iran, 2017. (In Persian)

9. Abdoli, G. Game Theory and its Applications (Static and Dynamic Game with Complete Information); Jahad daneshgahi Publication: Tehran, Iran, 2019. (In Persian)

10. Shahi, C.; Kant, S. An evolutionary game-theoretic approach to the strategies community members under Joint Forest Management regimes. For. Policy Econ. 2007, 9, 763-775. [CrossRef]

11. Mohammadi Limaei, S.; Lohmander, P. A game theory approach to the Iranian forest industry raw material market. Casp. J. Environ. Sci. 2008, 6, 59-71.

12. Mohammadi Limaei, S. Mixed strategy game theory, application in forest industry. For. Policy Econ. 2010, 12, 527-531. [CrossRef]

13. Soltani, A.; Sanskhayan, P.L.; Hofstad, O. Playing forest governance games: State-village conflict in Iran. For. Policy Econ. 2016, 73, 251-261. [CrossRef]

14. Zandebasiri, M.; Soosani, J.; Pourhashemi, M. Evaluating existing strategies in environmental crisis of Zagros forests of Iran. Appl. Ecol. Environ. Res. 2017, 15, 621-631. [CrossRef]

15. Iranian Forests, Rangelands and Watershed Organization. Guidelines for Sustainable Forest Ecosystem Management in Order to Prevent the Oak Mortality; Forests, Rangelands and Watershed Organization Publication: Tehran, Iran, 2013. (In Persian)

16. Jazirei, M.H.; Ebrahimi Rostaghi, M. Silviculture in Zagros Forests; University in Tehran Press: Tehran, Iran, 2011. (In Persian)

17. Zandebasiri, M.; Pourhashemi, M. The place of AHP among the multi criteria decision making methods in forest management. Int. J. Appl. Oper. Res. 2016, 6, 75-89.

18. Zandebasiri, M.; Hoseini, S.M. Sustainable Forest Management (SFM); Jahad Daneshgahi Press (Mazandaran Branch): Sari, Iran, 2019. (In Persian)

19. Imani Rastabi, M.; Jalilvand, H.; Zandebasiri, M. Assessment of socio-economic criteria and indicators in monitoring of Kalgachi Lordegan forest management plan. Iran. J. For. Poplar Res. 2005, 23, 1-8. (In Persian)

20. Ghazanfari, H.; Namiranian, M.; Sobhani, H.; Mohajer, R.M. Traditional forest management and its application to encourage public participation for sustainable forest management in the northern Zagros mountain of Kurdistan province, Iran. Scand. J. For. Res. 2004, 19, 65-71. [CrossRef]

21. Soltani, A.; Sanskhayan, P.L.; Hofstad, O. A dynamic bio-economic model for community management of goat and oak forests in Zagros, Iran. Ecol. Econ. 2014, 106, 174-185. [CrossRef]

22. Valipour, A.; Plieninger, T.; Shakeri, Z.; Ghazanfari, H.; Namiranian, M.; Lexer, M.J. Traditional silvopastoral management and its effects on forest stand structure in northern Zagros, Iran. For. Ecol. Manag. 2014, 327, 221-230. [CrossRef]

23. Pourhashemi, M.; Zandebasiri, M.; Panahi, P. Structural characteristics of oak coppice stands of Marivan Forests. Iran. J. Plant Res. 2004, 27, 766-776. (In Persian)

24. Zandebasiri, M.; Ghazanfari, H. The main consequences of affecting factors on forest management of local settlers in the Zagros forests (Case study: Ghalegol watershed in Lorestan province). Iran. J. For. 2010, 2, 127-138. (In Persian)

25. Zandebasiri, M.; Soosani, J.; Pourhashemi, M. Evaluation of the crisis severity in forests of Kohgiluye and Boyerahmad province (Case study: Tang-e Solak). Iran. J. For. Poplar Res. 2015, 24, 665-674. (In Persian)

26. Pourhashemi, M.; Dey, D.C.; Mehdifar, D.; Panahi, P.; Zandebasiri, M. Evaluating acorn crops in an oak-dominated stand to identify good acorn producers. Austrian J. For. Sci. 2018, 35, 213-234. 
27. Pourhashemi, M.; Panahi, P.; Zandebasiri, M. Application of visual surveys to estimate acorn production of Brant's oak (Quercus brantii Lindl.) in northern Zagros Forests of Iran. Casp. J. Environ. Sci. 2013, 11, 85-95.

28. Sagheb Talebi, K.; Sajedi, T.; Pourhashemi, M. Forests of Iran: A Treasure from the Past, a Hope for the Future; Springer: Berlin/Heidelberg, Germany, 2014.

29. Zandebasiri, M.; Parvin, T. Investigation on importance of Near East Process's criteria and indicators on sustainable management of Zagros forests (case study: Tange Solak Water Catchment, Kohgiloye and Boyer Ahmad province). Iran. J. For. Poplar Res. 2012, 20, 204-216.

30. Pourhashemi, M.; Zandebasiri, M.; Panahi, P. Estimation of acorn production of gall oak (Quercus infectoria Olivier) in Baneh forests by Koenig visual method. Iran. J. For. Poplar Res. 2011, 19, 194-205. (In Persian)

31. Hoseinzadeh, J.; Pourhashemi, M. The study of crown indicators in Quercus brantii tress in relationship with mortality phenomenon in Ilam forests. Iran. J. For. 2005, 7, 57-66. (In Persian)

32. Zandebasiri, M.; Ghazanfari, H.; Sepahvand, A.; Fatehi, P. Presentation of decision making pattern for Forest management Unit under uncertainty conditions (case study: Taf local area-Lorestan). Iran. J. For. 2011, 3, 109-120. (In Persian)

33. Zandebasiri, M.; Pourhashemi, M. Traditional forest related knowledge, Part 4: Management unit in Zagros forests. Iran. J. Nat. 2018, 12, 8-11. (In Persian)

34. Paletto, A.; Giacovelli, G.; Grilli, G.; Balest, J.; De Meo, I. Stakeholders' preferences and the assessment of forest ecosystem services: a comparative analysis in Italy. J. For. Sci. 2014, 60, 472-483. [CrossRef]

35. Salehnasab, A.; Feghhi, J.; Danehkar, A.; Soosani, J.; Dastranj, A. Forest park site selection based on a Fuzzy analytic hierarchy process framework (Case study: the Galegol Basin, Lorestan province, Iran). J. For. Sci. 2016, 62, 253-263. [CrossRef]

36. Soltani, A.; Angelsen, A.; Eid, T.; Noori Naieni, M.S.; Shamekhi, T. Poverty, sustainability, and household livelihood strategies in Zagros, Iran. Ecol. Econ. 2012, 79, 60-70. [CrossRef]

37. Zandebasiri, M.; Vacik, H.; Etongo, D.; Dorfstetter, Y.; Soosani, J.; Pourhashemi, M. Application of time-cost trade-off model in forest management projects. J. For. Sci. 2019, 65, 481-492. [CrossRef]

(C) 2020 by the authors. Licensee MDPI, Basel, Switzerland. This article is an open access article distributed under the terms and conditions of the Creative Commons Attribution (CC BY) license (http://creativecommons.org/licenses/by/4.0/). 